\title{
Concurrent E: Safe Communities 24 BUILDING A SUSTAINABLE SAFE COMMUNITIES NETWORK: THE AMERICAN EXPERIENCE
}

doi:10.1136/injuryprev-2012-040580a.24

D Stein-Harris*. National Safety Council/Safe Communities America, USA

Background Over the 20+ years of the International Safe Communities movement, the model did not gain traction in the USA until the National Safety Council (NSC) spearheaded the development of Safe Communities America in 2007. Since then, NSC has promoted this community-coalition model, mentored and supported communities, and now have a network of 21 successful, internationally designated communities, including three universities.

Aims/Objectives/Purpose The goal of the NSC/Safe Communities America network is to reduce the number of injuries and deaths in the USA.

Methods (1) Provide guidance, tools, training in evaluation, leadership, coalition building and sustainability through regular correspondence and hosting of an annual networking conference including training. (2) Initiate research that demonstrates that people living in a county that is a designated Safe Community are safer than comparable counties.

Results/Outcomes The networking conference provides a national forum for sharing proven and promising programmes. Communities have initiated key local strategies as a result of their participation in important injury areas that might not otherwise have been done. Results of our initial research indicates that communities that are designated Safe Communities have 9\% fewer fatalities than comparable counties in the US.

Significance By encouraging the development of Safe Communities through on-going mentoring, training, as well as providing evidence that their efforts are working, viable and sustainable networks have developed that will provide a continuous stream of new and innovative solutions to community safety. 